\title{
Intravenous Iron Treatment in the Prevention of Iron Deficiency and Anaemia After Roux-en-Y Gastric Bypass
}

\author{
Jorunn Sandvik ${ }^{1,2,3}$ (1) $\cdot$ Torstein Hole ${ }^{1,4} \cdot$ Christian A. Klöckner ${ }^{2,5} \cdot$ Bård Eirik Kulseng $^{2,3} \cdot$ Arne Wibe $^{6,7}$
}

Published online: 18 January 2020

(C) The Author(s) 2020

\begin{abstract}
Background Iron absorption is disturbed after Roux-en-Y gastric bypass (RYGB) and iron deficiency with or without anaemia affects almost half of all patients. Intravenous iron is an option when per oral iron is insufficient or not tolerated. This study explores whether routinely offering intravenous iron treatment when iron stores are empty can prevent anaemia and iron deficiency after RYGB.

Methods This is a study of prospectively registered data on clinical information, haematological tests and intravenous iron treatment from 644 RYGB patients who underwent surgery between 2004 and 2013, postoperatively followed more than 5 years. Intravenous iron treatment was offered to patients with ferritin $\leq 15 \mu \mathrm{g} / \mathrm{L}$.

Results Clinical information was available for all patients at baseline and for 553/644 patients at 5 years; laboratory results were available for 540/644 patients at baseline and 411/644 patients after 5 years. The mean age was $39.8( \pm 9.7)$ years. Overall, 187/483 (38.7\%) women and 9/161 (5.6\%) men were given intravenous iron treatment in the observation period. From baseline to 5 years, mean haemoglobin decreased by $0.3 \mathrm{~g} / \mathrm{dL}$ in both men and women. Anaemia occurred in 18/311 (5.8\%) women and 9/100 (9\%) men at 5 years. Depleted iron stores (ferritin $\leq 15 \mu \mathrm{g} / \mathrm{L}$ ) were seen among 44/323(13.6\%) women and 3/102 (2.9\%) men, and low iron stores (ferritin 16-50 $\mu \mathrm{g} / \mathrm{L}$ ) occurred in 144/326 (44.6\%) women and 38/102 (37.3\%) men 5 years after RYGB.

Conclusion By routinely offering intravenous iron treatment to patients with depleted iron stores after RYGB, haemoglobin levels were preserved. Half of the patients experienced low or depleted iron stores at 5 years.
\end{abstract}

Keywords Iron deficiency · Anaemia · Intravenous iron replacement · RYGB · Gastric bypass · Bariatric surgery · Iron deficiency anaemia $\cdot$ Iron deficiency without anaemia $\cdot$ Iron deficiency after RYGB

\section{Introduction}

Roux-en-Y gastric bypass (RYGB) has been a common bariatric procedure for more than 50 years [1], and more than

Jorunn Sandvik

jorunn.sandvik@stolav.no; jorunn.sandvik@mimer.no

Torstein Hole

torstein.hole@helse-mr.no

Christian A. Klöckner

christian.klockner@ntnu.no

Bård Eirik Kulseng

bard.kulseng@stolav.no

Arne Wibe

arne.wibe@ntnu.no

1 Clinic of Medicine and Rehabilitation, Møre and Romsdal Hospital Trust, Alesund, Norway
$30 \%$ of the 635,000 patients worldwide undergoing a bariatric procedure each year get RYGB [2]. This procedure implies that the food bolus bypasses the main part of the stomach, the duodenum and the proximal jejunum, and instead passes
2 Center for Obesity, Department of Surgery, St. Olav Hospital, Trondheim University Hospital, Trondheim, Norway

3 Department of Clinical and Molecular Medicine, Obesity Research Group, Norwegian University of Science and Technology, Trondheim, Norway

4 Faculty of Medicine and Health Sciences, Norwegian University of Science and Technology, Trondheim, Norway

5 Department of Psychology, NTNU - Norwegian University of Science and Technology, Trondheim, Norway

6 Department of Clinical and Molecular Medicine, Norwegian University of Science and Technology, Trondheim, Norway

7 Department of Surgery, St. Olav Hospital, Trondheim University Hospital, Trondheim, Norway 
through an alimentary limb of $1 \mathrm{~m}$ or more before the food blends with bile and pancreatic enzymes. The aim of this procedure is to reduce capacity for food intake and absorption of energy from the food. The downside is that the main sites for absorption of essential vitamins and minerals, like folate, vitamin $\mathrm{B}_{12}$, calcium and iron, are also bypassed, and nutritional elements dependent on acidic environments are less likely to be absorbed [3]. Patients are advised to use supplements of micronutrients to compensate for the reduced absorption and regularly monitor their levels of micronutrients by blood tests $[4,5]$.

Anaemia has been reported in up to half of the patients 5 years after RYGB, and iron deficiency is even more frequent, due to a combination of lack of intake of iron-rich food and lack of iron absorption [6-8]. Most of the iron used by the cells is recycled, but a daily iron uptake of $1-2 \mathrm{mg}$ is needed to replace the iron losses caused by shedding of epithelial cells from the skin and intestines, menstrual blood and sweat. Symptoms of anaemia are well known, but there is less awareness of symptoms of iron deficiency with normal haemoglobin levels [9].

In addition to haematopoiesis, iron is an essential component of myoglobin in the muscles, necessary for optimal function of neurons, and it is an important element of mitochondrial activity and energy production [10-13]. Iron deficiency without anaemia is a potential cause of fatigue, decreased exercise performance and cognitive impairment, symptoms which are frequently reported after bariatric surgery [14-20].

Iron homeostasis differs from other minerals by having a complex regulation of absorption, recycling and storage, but no mechanism for excretion of surplus iron, and iron overload is toxic $[17,21]$. Iron is mainly absorbed by the enterocytes in the duodenum and proximal jejunum, areas that are bypassed after RYGB, but small amounts of iron can be absorbed by the more distal parts of the gastrointestinal tract [22]. The hepatic hormone hepcidin is central in regulating iron absorption from the intestinal lumen to the enterocytes, as well as the transfer of iron from the enterocytes to the blood [23, 24]. When hepcidin levels are high, iron absorption is low. High doses of per oral iron supplements can increase hepcidin and thereby block iron absorption $[25,26]$.

In clinical settings, iron stores are best assessed by serum ferritin levels [27]. Ferritin plays a major role in iron sequestration and transport, and low ferritin levels are diagnostic for iron deficiency [28]. However, ferritin levels are increased by inflammation, and iron deficiency can therefore coexist with high ferritin levels [29]. The cut-off level for depleted iron stores recommended by WHO is $<15 \mu \mathrm{g} / \mathrm{L}$ for adults [30]. However, higher and lower gender-specific thresholds for ferritin have been used. A ferritin level of $30 \mu \mathrm{g} / \mathrm{L}$ is the most sensitive $(92 \%)$ and specific (98\%) cut-off level for absolute iron deficiency [31]. Haemoglobin levels will remain normal until the iron stores are depleted, and normal haemoglobin levels do not exclude empty iron stores [32].

International guidelines recommend oral iron supplement to prevent iron deficiency and anaemia after bariatric surgery, and intravenous iron treatment if per oral treatment fails [4]. If the iron stores are emptied, it may take several months to restore them by per oral iron supplements [7]. Intravenous iron treatment is a safe procedure that restores iron stores in less time, but access to this treatment can be limited due to financial and organizational causes [9, 33, 34]. In studies published thus far, the indications for intravenous iron treatment after bariatric surgery have been anaemia or per oral iron treatment failure, and less than $10 \%$ of the patients have received this treatment after RYGB $[6,35,36]$. The same studies report anaemia in until $30 \%$ of the patients. The aim of this study was to explore whether routinely offering intravenous iron treatment to patients with depleted iron stores after RYGB, regardless of haemoglobin levels, preserved iron stores and prevented iron deficiency anaemia 5 years after surgery.

\section{Material}

This study is a retrospective analysis of prospectively collected data on 644 patients who underwent RYGB as a primary treatment for severe obesity at a public hospital from 2004 to 2013 with a postoperative follow-up of more than 5 years.

The RYGB procedure was performed with laparoscopic antecolic, antegastric technique, using a biliopancreatic limb of 40-60 cm and an alimentary limb of $100 \mathrm{~cm}$ or $150 \mathrm{~cm}$, depending on BMI below or above $50 \mathrm{~kg} / \mathrm{m}^{2}$ [37].

The patients were enrolled in a local quality registry and followed a standardized clinical pathway according to international guidelines at the time [38]. A standardized set of lab tests was taken 1 year before the RYGB procedure and at 2,6 , $12,18,24,36,48$ and 60 months after the operation.

Data on weight, comorbidity, complications and other relevant events in the postoperative period were registered. In addition to information from planned visits in the follow-up program of 5 years, information on intravenous iron treatment was recorded until 14 years after RYGB. Results from laboratory tests related to the 5-year outpatient follow-up program were added to the quality registry by collecting data directly from the hospital's laboratory data system. The registry was last updated January 2019. Laboratory results were available in the registry for $544(84 \%)$ patients at baseline and 428 $(66 \%)$ after 5 years.

The over-the-counter multivitamin-mineral product most commonly used in this cohort contained $15 \mathrm{mg}$ iron (II) fumarate and $400 \mu \mathrm{g}$ folate per unit. In general, the patients were advised to use additional per oral iron supplements with ascorbic acid for 1 month twice a year if ferritin was $>50 \mu \mathrm{g} / \mathrm{L}$, or more often if the ferritin values were lower. Patients with 
ferritin levels above the normal range were advised not to take iron supplements. The patients were also recommended supplemental vitamin $\mathrm{B}_{12}$ and calcium with vitamin $\mathrm{D}$, and they were offered intravenous iron treatment if the iron stores were depleted, defined as ferritin $\leq 15 \mu \mathrm{g} / \mathrm{L}$.

\section{Methods}

Continuous variables are given as means \pm standard deviation (SD) if normally distributed, and median with interquartile range (IQR) in non-normally distributed variables. Categorical variables are reported in numbers and percentages. Independent $t$ tests were performed for normally distributed variables, and non-parametric tests were used for nonnormally distributed variables. $\chi^{2}$ tests were performed for categorical variables. Differences were considered to be significant at $p<0.05$.

Iron stores were graded as depleted (ferritin $\leq 15 \mu \mathrm{g} / \mathrm{L}$ ), low (ferritin 16-50 $\mu \mathrm{g} / \mathrm{L}$ ), moderate (ferritin 51-100 $\mu \mathrm{g} / \mathrm{L}$ ), and replete (ferritin $>100 \mu \mathrm{g} / \mathrm{L}$ ). Intravenous iron treatment was given mainly as ferric carboxymaltose $1 \mathrm{~g}$ in one visit and less often as iron sucrose $200 \mathrm{mg}$ over five visits. Blood transfusions for iron deficiency anaemia were not given unless there was an acute medical situation, like haemorrhage after elective or acute surgery, in the observation period.

Statistical analyses were performed using IBM SPSS version 25 (SPSS Inc., Chicago, IL, USA) and STATA 14 (StataCorp).

\section{Results}

A total of 644 patients underwent RYGB as a primary bariatric surgery for severe obesity from 2004 to 2013. Mean (SD) age was $39.8 \pm 9.7$ years, and $75 \%$ of the patients were women. In the observation period of 5 to 14 years, mean $112 \pm$ 29.3 months, fifteen $(2.3 \%)$ patients have died, two of them in the early postoperative period. Baseline body mass index
(BMI) was $43.9 \pm 5.1 \mathrm{~kg} / \mathrm{m}^{2}$ and percentage total weight loss (\%TWL) at 5 years was $27.6 \pm 10.1 \mathrm{~kg} / \mathrm{m}^{2}$ (Table 1).

Median (IQR) ferritin changed from $61(36-100) \mu \mathrm{g} / \mathrm{L}$ to $43(23-69) \mu \mathrm{g} / \mathrm{L}$ in women, and from $173(123-265) \mu \mathrm{g} / \mathrm{L}$ to $62(40-93) \mu \mathrm{g} / \mathrm{L}$ in men before to 5 years after RYGB (Table 2).

The number of patients experiencing iron depletion increased from $25 / 399$ (6.3\%) before RYGB to $44 / 323$ $(13.6 \%)$ after 5 years among women and from 1/143 $(0.7 \%)$ to $3 / 102(2.9 \%)$ among men. The number of patients with low iron stores (ferritin 16-50 $\mu \mathrm{g} / \mathrm{L}$ ) was 141/399 (35.3\%) before RYGB and 144/323 (44.6\%) after 5 years among women and $5 / 143(3.5 \%)$ before and 38/192 (37.3\%) after 5 years among men (Figs. 1 and 2). The mean reduction in ferritin values in the 5 years after RYGB was $40 \pm 85 \mu \mathrm{g} / \mathrm{L}$ in women and 105 $\pm 83 \mu \mathrm{g} / \mathrm{L}$ in men (Fig. 3).

In the Scandinavian population, anaemia has been defined as haemoglobin $<12.0 \mathrm{~g} / \mathrm{dL}$ in women and haemoglobin < $13.7 \mathrm{~g} / \mathrm{dL}$ in men [39]. According to these definitions, anaemia occurred in 13/451 (2.9\%) of women and 7/158 (4.4\%) of men at RYGB, in 36/382 (9.4\%) of women and $16 / 122$ (13.1\%) of men after 2 years, and in 18/311 (5.8\%) of women, and $9 / 100(9.0 \%)$ of men 5 years after RYGB.

Mean haemoglobin levels changed from $13.7 \pm 1.0 \mathrm{~g} /$ $\mathrm{dL}$ before to $13.4 \pm 1.0 \mathrm{~g} / \mathrm{dL} 5$ years after RYGB in women $(p<0.001)$ and from $15.2 \pm 0.95 \mathrm{~g} / \mathrm{dL}$ to $14.9 \pm 0.95 \mathrm{~g} /$ $\mathrm{dL}$ in men $(p<0.001)$ (Fig. 4). Annual values are given in Table 2 .

With a mean observation time of $9.25 \pm 2.4$ years after RYGB, a total of $196 / 644(30.4 \%)$ patients, $187 / 483$ (38.7\%) women and 9/161 (5.6\%) men, had one or more intravenous iron treatments. Median (IQR) time from RYGB to first intravenous iron was $3(2-4)$ years for women and 4 (2-7) years for men. Among the patients who were given intravenous iron treatment, 102 (16\% of the study population) were given one treatment, 42 (6.6\% of the study population) were given two treatments and 27 (4.2\% of the study population) were given three treatments in the observation period. Thirty-two patients (5\% of the study population) had their first intravenous iron treatment more than 5 years after RYGB.

Table 1 Patients' characteristics

\begin{tabular}{llll}
\hline & All, $N=644$ & Female, $n=483$ & Male, $n=161$ \\
\hline Age*(years) & $39.8 \pm 9.7 ; 644$ & $39.4 \pm 9.6 ; 483$ & $40.9 \pm 10.1 ; 161$ \\
BMI baseline* $\left(\mathrm{kg} / \mathrm{m}^{2}\right)$ & $43.9 \pm 5.1 ; 644$ & $43.8 \pm 4.8 ; 483$ & $44.3 \pm 5.7 ; 161$ \\
BMI nadir* $\left(\mathrm{kg} / \mathrm{m}^{2}\right)$ & $28.5 \pm 4.3 ; 633$ & $28.0 \pm 4.1 ; 474$ & $29.7 \pm 4.3 ; 159$ \\
BMI 5 years* $\left(\mathrm{kg} / \mathrm{m}^{2}\right)$ & $31.6 \pm 5.3 ; 553$ & $31.2 \pm 5.5 ; 418$ & $32.6 \pm 4.5 ; 135$ \\
\%TWL nadir* $(\%)$ & $35.3 \pm 7.8 ; 633$ & $36.1 \pm 7.5 ; 474$ & $32.8 \pm 8.0 ; 159$ \\
\%TWL 5 years* $(\%)$ & $27.6 \pm 10.1 ; 533$ & $28.3 \pm 10.2 ; 418$ & $25.2 \pm 9.3 ; 135$ \\
\%EWL 5 years* $(\%)$ & $65.8 \pm 24.4 ; 533$ & $67.8 \pm 25.0 ; 418$ & $59.9 \pm 21.6 ; 135$ \\
\hline
\end{tabular}

$*$ Mean $\pm \mathrm{SD}, B M I$ body mass index, $\% T W L$ percentage total weight loss, $\% E W L$ percentage excess weight loss 
The levels of folate and vitamin $\mathrm{B}_{12}$ increased after RYGB, indicating that most patients were adherent to the recommended supplements.

\section{Discussion}

The main findings in this study are that during the first 5 years after RYGB; more than one out of four patients were given intravenous iron treatment when this treatment was routinely offered to iron depleted patients. There was a minor decrease in mean haemoglobin levels in the group, but a substantial increase in the proportion of patients with low or depleted iron stores 5 years after RYGB.

Compared with other studies, intravenous iron treatment was more widely applied in the present cohort and also given to patients without anaemia if ferritin levels were low [7, 35]. However, half of those who were in need of intravenous iron only had a single treatment over the average observation time of 9 years. This could be due to better compliance to per oral prophylactic treatment, improvement in iron absorption over time, food modifications or treatment for underlying disease after the first treatment with intravenous iron. It is also possible that iron deficiency was less likely to be diagnosed when the follow-up was handed over from the bariatric outpatient clinic to primary health care 5 years after RYGB.

In a systematic review on iron deficiency after RYGB and sleeve gastrectomy with an average follow-up time of 27.8 months, the overall incidence of iron deficiency anaemia were $14.8 \%$ post-RYGB, and iron deficiency occurred in $22.5 \%$ [40]. Only two of the studies included in the review reported on intravenous iron treatment.

In a retrospective study by Obinwanne, $53 \%$ of the RYGB patients were found to have ferritin $<50 \mu \mathrm{g} / \mathrm{L}$ at some point in the postoperative period [6]. In this study, only $6.7 \%$ of the patients were given intravenous iron treatment, and mean haemoglobin changed from $13.5 \mathrm{~g} /$ $\mathrm{dL}$ preoperatively to $11.6 \mathrm{~g} / \mathrm{dL}$ more than 5 years after RYGB. Compared with the present study, the proportion of patients with ferritin $<50 \mu \mathrm{g} / \mathrm{L}$ is almost at the same level, but the fall in haemoglobin of $1.9 \mathrm{~g} / \mathrm{dL}$ compared with $0.3 \mathrm{~g} / \mathrm{dl}$ may be due to a lesser extent of intravenous iron treatment. In another retrospective study where no use of intravenous iron was reported, a quarter of the women were anaemic, and $42 \%$ had depleted iron stores 5 years after RYGB [41].

The number of post-bariatric patients is continually increasing, and the capacity at specialized centres for individualized follow-up is limited. However, lifelong followup is important to avoid vitamin and mineral deficiencies. For water-soluble vitamins and minerals, general 
Fig. 1 Serum ferritin from before to 5 years after RYGB in men

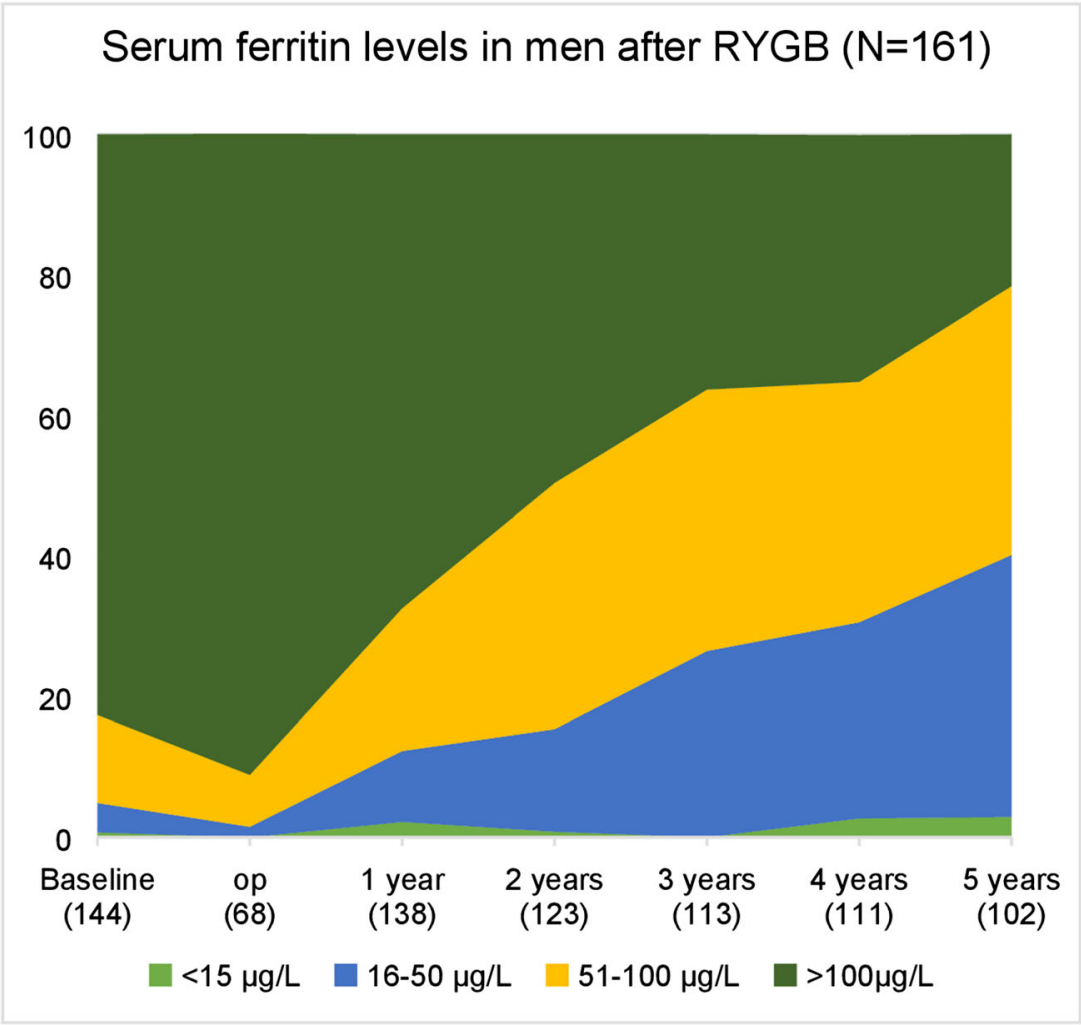

recommendations are feasible. Iron supplement, however, needs to be individualized, and as the regulation of iron uptake is complex, there is a need for educating patients as well as primary health care providers on how to avoid
Fig. 2 Serum ferritin from baseline to 5 years after RYGB in women

\section{Serum ferritin levels in women after RYGB $(\mathrm{N}=483)$}

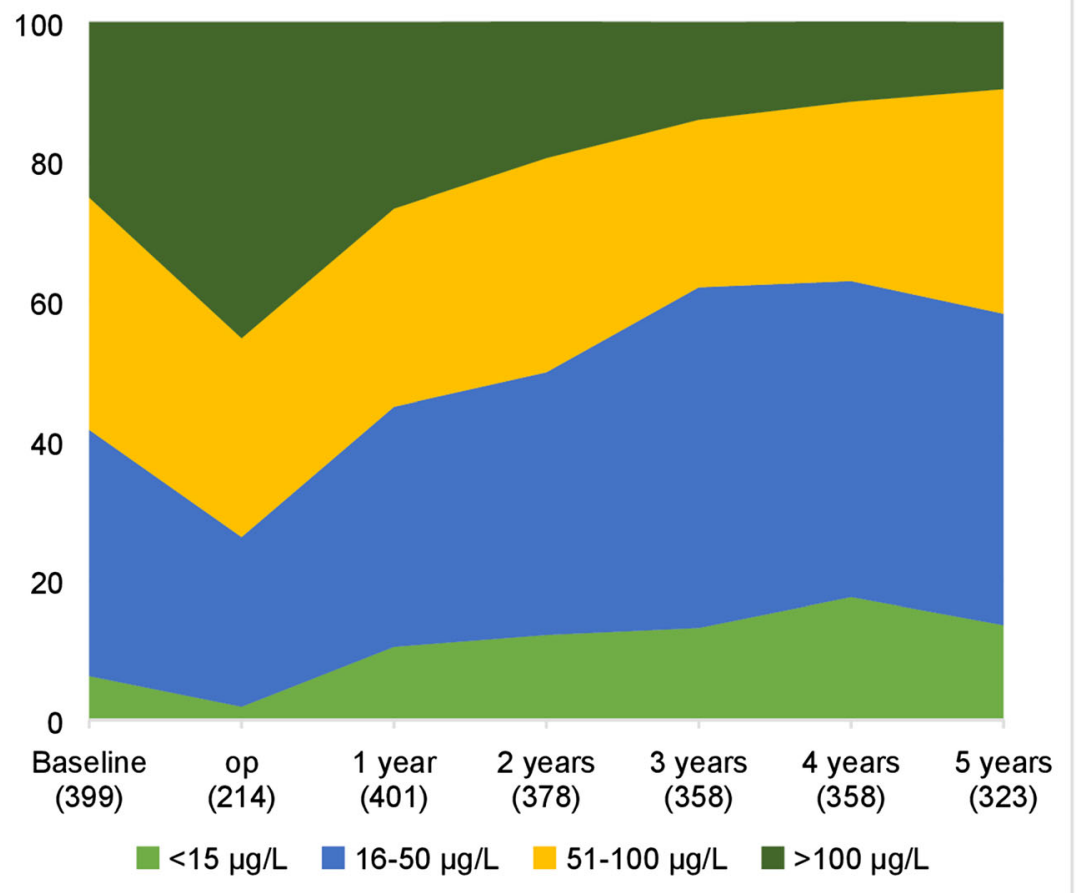


Fig. 3 Mean change in ferritin $(\mu \mathrm{g} / \mathrm{L})$ after RYGB. Asterisk means ferritin before RYGB might be increased due to obesity induced inflammation; the ferritin value $1-2$ months after RYGB are used as reference

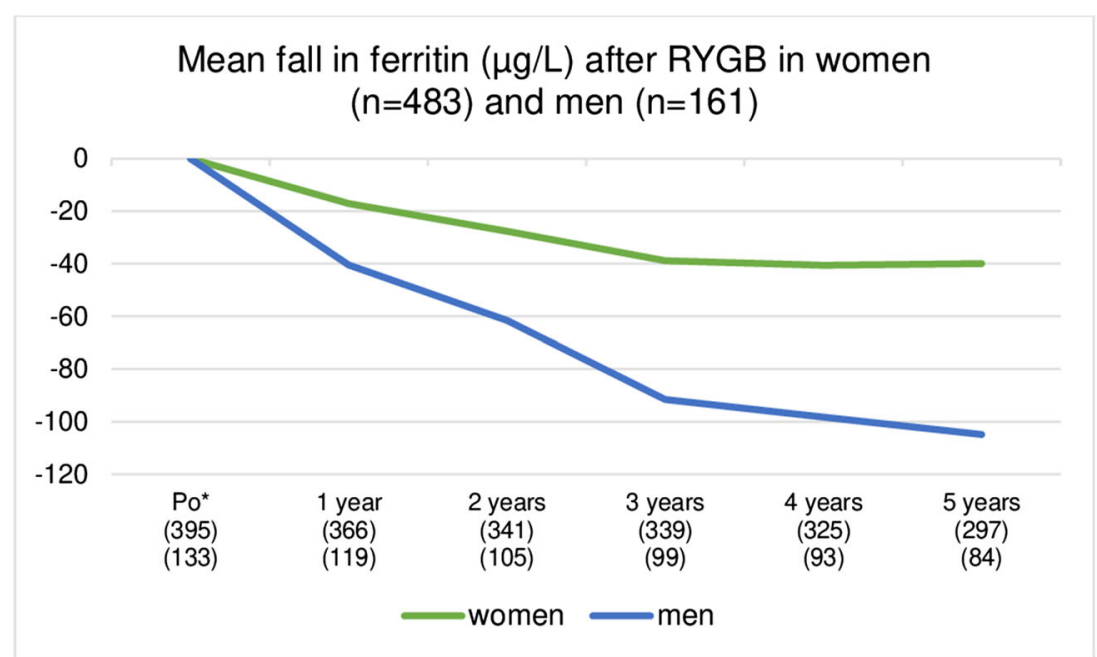

iron deficiency as well as overuse of iron supplements after bariatric surgery.

According to the findings in the present study, access to intravenous iron treatment when iron stores are empty prevents anaemia 5 years after RYGB in women, but not to the same degree in men. To prevent low or depleted iron stores after RYGB, an even more liberal indication for intravenous iron treatment might be necessary.

Iron deficiency even in the absence of anaemia has been related to fatigue and lower ability to respond to increases in mental and physical workload [42]. Fatigue is a major complaint among RYGB patients [19]. In non-anaemic iron-deficient adults, iron supplementation has been associated with reduced fatigue, although without any objective measurements of improved physical capacity [43, 44]. The present study did not contain systematic information on fatigue or other symptoms that could be related to iron deficiency, and any connection between fatigue and low iron stores could not be explored.

\section{Strengths and Limitations}

The strength of this study was the close follow-up of the patients in a standardized post-operative program with haematological results of more than $65 \%$ of the patients at each point in time. All treatments with intravenous iron were registered prospectively.

The limitations were the lack of systematic information on symptoms, ferritin and haemoglobin levels before and after each intravenous iron treatment, and that haematological results were not collected for more than 5 years after RYGB. Also, there was no information recorded on menstrual status or to what degree the patients followed the recommendations on per oral iron supplements.
Fig. 4 Mean haemoglobin levels from baseline to 5 years after RYGB

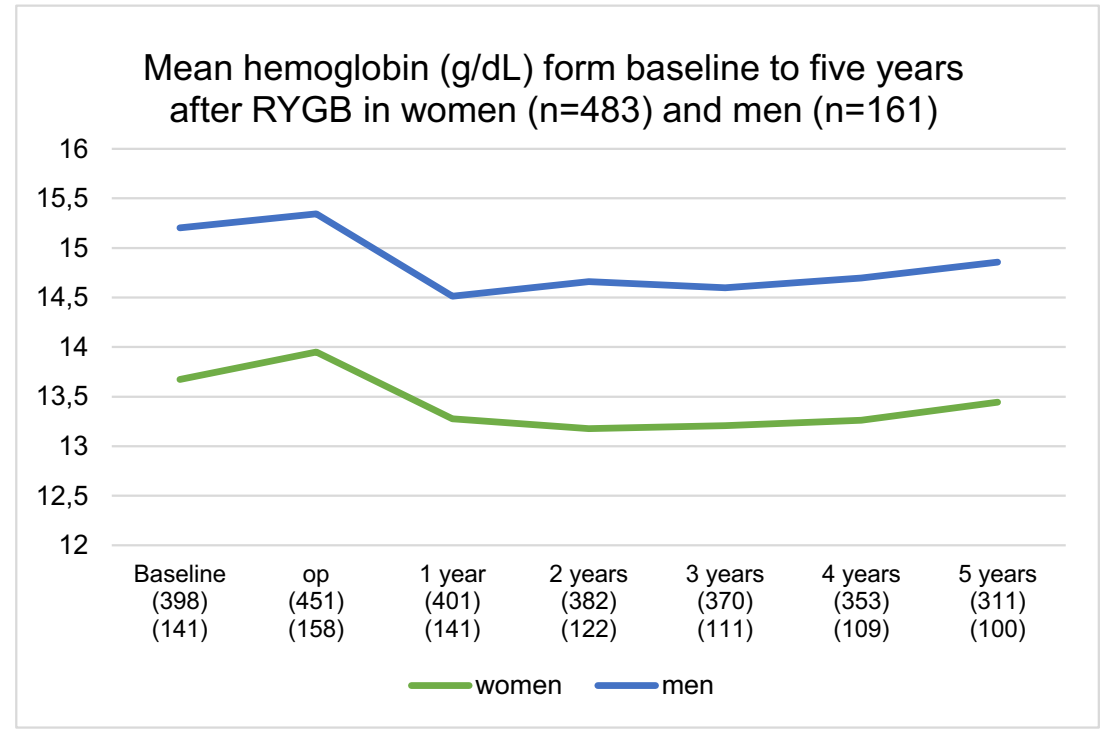




\section{Conclusion}

Iron deficiency and anaemia are common in the long run after RYGB. Individualized advice on iron supplements and access to intravenous iron treatment when iron stores were depleted seemed to reduce the frequency of anaemia, but did not prevent iron deficiency in the present study. Major falls in iron stores appeared more than 2 years after surgery, when many patients are no longer followed in bariatric outpatient clinics. The primary health care providers might not be aware of the need for lifelong individualized iron supplements for RYGB patients. The clinical relevance of low iron stores after RYGB needs further investigation. If there is an association between iron deficiency and fatigue among these patients, better access to intravenous iron treatment can contribute to improve health after RYGB.

Funding Information Open Access funding provided by NTNU Norwegian University of Science and Technology (incl St. Olavs Hospital - Trondheim University Hospital). This study was founded by a grant from Helse Møre og Romsdal Hospital trust.

\section{Compliance with Ethical Standards}

The study was evaluated by the Regional Ethics Committee (REK 2016/331) as a QUALITY improvement project and approved by the local Data Protection Officer. All procedures performed in studies involving human participants were in accordance with the ethical standards of the institutional and/or national research committee and with the 1964 Helsinki declaration and its later amendments or comparable ethical standards. For this type of study, formal consent is not required.

Conflict of Interest The authors declare that they have no conflict of interest.

Open Access This article is licensed under a Creative Commons Attribution 4.0 International License, which permits use, sharing, adaptation, distribution and reproduction in any medium or format, as long as you give appropriate credit to the original author(s) and the source, provide a link to the Creative Commons licence, and indicate if changes were made. The images or other third party material in this article are included in the article's Creative Commons licence, unless indicated otherwise in a credit line to the material. If material is not included in the article's Creative Commons licence and your intended use is not permitted by statutory regulation or exceeds the permitted use, you will need to obtain permission directly from the copyright holder. To view a copy of this licence, visit http://creativecommons.org/licenses/by/4.0/.

\section{References}

1. Mason EE, Ito C. Gastric bypass in obesity. Surg Clin North Am. 1967;47(6):1345-51.

2. Angrisani L, Santonicola A, Iovino P, et al. IFSO Worldwide Survey 2016: primary, endoluminal, and revisional procedures. Obes Surg. 2018;28(12):3783-94.

3. Via MA, Mechanick JI. Nutritional and micronutrient care of bariatric surgery patients: current evidence update. Curr Obes Rep. 2017;6(3):286-96.
4. Fried M, Yumuk V, Oppert JM, et al. Interdisciplinary European guidelines on metabolic and bariatric surgery. Obes Facts. 2013;6(5):449-68.

5. Mechanick JI, Apovian C, Brethauer S, et al. Clinical practice guidelines for the perioperative nutrition, metabolic, and nonsurgical support of patients undergoing bariatric procedures - 2019 update: cosponsored by American Association of Clinical Endocrinologists/American College of Endocrinology, the obesity society, American Society for Metabolic \& Bariatric surgery, Obesity Medicine Association, and American Society of Anesthesiologists. Endocr Pract. 2019;25(12):1346-59. https:// doi.org/10.4158/GL-2019-0406.

6. Obinwanne KM, Fredrickson KA, Mathiason MA, et al. Incidence, treatment, and outcomes of iron deficiency after laparoscopic Roux-en-Y gastric bypass: a 10-year analysis. J Am Coll Surg. 2014;218(2):246-52.

7. ten Broeke R, Bravenboer B, Smulders FJ. Iron deficiency before and after bariatric surgery: the need for iron supplementation. Neth J Med. 2013;71(8):412-7.

8. Gesquiere I, Lannoo M, Augustijns P, et al. Iron deficiency after Roux-en-Y gastric bypass: insufficient iron absorption from oral iron supplements. Obes Surg. 2014;24(1):56-61.

9. Munoz M, Gomez-Ramirez S, Besser M, et al. Current misconceptions in diagnosis and management of iron deficiency. Blood Transfus. 2017;15(5):422-37.

10. Evstatiev R, Gasche C. Iron sensing and signalling. Gut. 2012;61(6):933-52.

11. Ghosh K. Non haematological effects of iron deficiency - a perspective. Indian J Med Sci. 2006;60(1):30-7.

12. Benotti PN, Wood GC, Still CD, et al. Metabolic surgery and iron homeostasis. Obes Rev. 2019;20(4):612-20.

13. Dziegala M, Josiak K, Kasztura M, et al. Iron deficiency as energetic insult to skeletal muscle in chronic diseases. J Cachexia Sarcopenia Muscle. 2018;9(5):802-15.

14. Gribsholt SB, Svensson E, Richelsen B, et al. Rate of acute hospital admissions before and after Roux-en-Y gastric bypass surgery: a population-based cohort study. Ann Surg. 2018;267(2):319-25.

15. Berg A. Untold stories of living with a bariatric body: long-term experiences of weight-loss surgery. Sociol Health Illn. 2019. https:// doi.org/10.1111/1467-9566.12999.

16. Pratt JJ, Khan KS. Non-anaemic iron deficiency - a disease looking for recognition of diagnosis: a systematic review. Eur J Haematol. 2016;96(6):618-28.

17. Silva B, Faustino P. An overview of molecular basis of iron metabolism regulation and the associated pathologies. Biochim Biophys Acta. 2015;1852(7):1347-59.

18. Stugiewicz M, Tkaczyszyn M, Kasztura M, et al. The influence of iron deficiency on the functioning of skeletal muscles: experimental evidence and clinical implications. Eur J Heart Fail. 2016;18(7): 762-73.

19. Gribsholt SB, Pedersen AM, Svensson E, et al. Prevalence of selfreported symptoms after gastric bypass surgery for obesity. JAMA Surg. 2016;151(6):504-11.

20. Yokoi K, Konomi A. Iron deficiency without anaemia is a potential cause of fatigue: meta-analyses of randomised controlled trials and cross-sectional studies. Br J Nutr. 2017;117(10):1422-31.

21. Yiannikourides A, Latunde-Dada GO. A short review of iron metabolism and pathophysiology of iron disorders. Medicines. 2019;6(3):85.

22. Fuqua BK, Vulpe CD, Anderson GJ. Intestinal iron absorption. J Trace Elem Med Biol. 2012;26(2-3):115-9.

23. Camaschella C. New insights into iron deficiency and iron deficiency anemia. Blood Rev. 2017;31(4):225-33.

24. Tussing-Humphreys L, Pusatcioglu C, Nemeth E, et al. Rethinking iron regulation and assessment in iron deficiency, anemia of chronic 
disease, and obesity: introducing hepcidin. J Acad Nutr Diet. 2012;112(3):391-400.

25. Anderson GJ, Frazer DM. Current understanding of iron homeostasis. Am J Clin Nutr. 2017;106(Suppl 6):1559s-66s.

26. Moretti D, Goede JS, Zeder C, et al. Oral iron supplements increase hepcidin and decrease iron absorption from daily or twice-daily doses in iron-depleted young women. Blood. 2015;126(17):1981-9.

27. Camaschella C. Iron deficiency. Blood. 2019;133(1):30-9.

28. Knovich MA, Storey JA, Coffman LG, et al. Ferritin for the clinician. Blood Rev. 2009;23(3):95-104.

29. Dignass A, Farrag K, Stein J. Limitations of serum ferritin in diagnosing iron deficiency in inflammatory conditions. Int J Chronic Dis. 2018;2018:9394060.

30. WHO. Serum ferritin concentrations for the assessment of iron status and iron deficiency in populations. Vitamin and Mineral Nutrition Information System Geneva, World Health Organization, 2011 (WHO/NMH/NHD/MNM/112) 2011. http:// www.who.int/vmnis/indicators/serum ferritin. pdf. Accessed 2019.

31. Munoz M, Botella-Romero F, Gomez-Ramirez S, et al. Iron deficiency and anaemia in bariatric surgical patients: causes, diagnosis and proper management. Nutr Hosp. 2009;24(6):640-54.

32. Cappellini MD, Musallam KM, Taher AT. Iron deficiency anaemia revisited. J Intern Med. 2019. https://doi.org/10.1111/joim.13004.

33. Elstrott $\mathrm{B}, \mathrm{Khan} \mathrm{L}, \mathrm{Olson} \mathrm{S}$, et al. The role of Iron repletion in adult Iron deficiency anemia and other diseases. Eur J Haematol. 2019. https://doi.org/10.1111/ejh.13345.

34. Naqash A, Ara R, Bader GN. Effectiveness and safety of ferric carboxymaltose compared to iron sucrose in women with iron deficiency anemia: phase IV clinical trials. BMC Womens Health. 2018;18(1):6.

35. Kotkiewicz A, Donaldson K, Dye C, et al. Anemia and the need for intravenous Iron infusion after Roux-en-Y gastric bypass. Clin Med Insights Blood Disord. 2015;8:9-17.

36. Malone M, Alger-Mayer S, Lindstrom J, et al. Management of iron deficiency and anemia after Roux-en-Y gastric bypass surgery: an observational study. Surg Obes Relat Dis. 2013;9(6):969-74.
37. Olbers T, Lonroth H, Fagevik-Olsen M, et al. Laparoscopic gastric bypass: development of technique, respiratory function, and longterm outcome. Obes Surg. 2003;13(3):364-70.

38. Mechanick JI, Kushner RF, Sugerman HJ, et al. American Association of Clinical Endocrinologists, the Obesity Society, and American Society for Metabolic \& Bariatric Surgery Medical Guidelines for Clinical Practice for the perioperative nutritional, metabolic, and nonsurgical support of the bariatric surgery patient. Surg Obes Relat Dis. 2008;4(5 Suppl):S109-84.

39. Nordin G, Martensson A, Swolin B, et al. A multicentre study of reference intervals for haemoglobin, basic blood cell counts and erythrocyte indices in the adult population of the Nordic countries. Scand J Clin Lab Invest. 2004;64(4):385-98.

40. Enani G, Bilgic E, Lebedeva E, et al. The incidence of iron deficiency anemia post-Roux-en-Y gastric bypass and sleeve gastrectomy: a systematic review. Surg Endosc. 2019. https://doi.org/10. 1007/s00464-019-07092-3.

41. Engebretsen KV, Blom-Hogestol IK, Hewitt S, et al. Anemia following Roux-en-Y gastric bypass for morbid obesity; a 5-year follow-up study. Scand J Gastroenterol. 2018;53(8):917-22.

42. Wenger MJ, DellaValle DM, Murray-Kolb LE, et al. Effect of iron deficiency on simultaneous measures of behavior, brain activity, and energy expenditure in the performance of a cognitive task. Nutr Neurosci. 2019;22(3):196-206.

43. Houston BL, Hurrie D, Graham J, et al. Efficacy of iron supplementation on fatigue and physical capacity in non-anaemic irondeficient adults: a systematic review of randomised controlled trials. BMJ Open. 2018;8(4):e019240.

44. Vaucher P, Druais PL, Waldvogel S, et al. Effect of iron supplementation on fatigue in nonanemic menstruating women with low ferritin: a randomized controlled trial. CMAJ. 2012;184(11):1247-54.

Publisher's Note Springer Nature remains neutral with regard to jurisdictional claims in published maps and institutional affiliations. 